\title{
Effects of skin and hide defects on quality grades and physical characteristics of crust leather
}

\author{
Tewelde Tsigab ${ }^{1}$, Abrha Bsrat ${ }^{1}$, Redae Alemayohu ${ }^{2}$, Mengstu Ashebre Arefe ${ }^{2}$, Niraj \\ Kumar $^{1}$, Birhanu Hadush ${ }^{1 *}$ \\ ${ }^{1}$ College of Veterinary Sciences, Mekelle University, Mekelle, Tigray, Ethiopia \\ ${ }^{2}$ Department of Manufacturing Engineering, Ethiopian Institute of Technology, Mekelle Univer- \\ sity, Mekelle, Tigray, Ethiopia \\ ${ }^{*}$ Corresponding author: birhanu.hadush@mu.edu.et, ORCID, 0000-0003-3614-595X, Tel: +251 \\ 919366578
}

\begin{abstract}
Leather is one of the important export commodities in Ethiopia. However, its quality and physical characteristics are affected by diseases, handling and storage problems. A cross-sectional study was conducted to identify major hide and skin defects and assess their effect on quality grades and physical characteristics of crust leather. A total of 6530 hides and skins were inspected at Sheba Tannery and Leather Industry Private Limited Company (PLC) through standard operative procedures. For tests on physical characteristics of crust leather, top 6 defects of skin and hide were identified thereby each 5 -crust leather per defect were evaluated by standard experiments for determining testing tensile strength, tear strength and percentage elongation at break. The overall hide and skin rejection was $32.7 \%$. The rejection in wet blue hide (23.5\%) was higher than for wet blue salted and dry goatskins (5.1\%) and pickled sheepskins (4.1\%). Scratch (20.5\%), Wound (14.6\%) and Cockle (12.7\%), were the most common pre-slaughter skin and hide defects found in wet blue hide, goatskin and pickled sheepskin, respectively. Knife cut with proportion of $21.1 \%, 17.5 \%$ and $4.5 \%$ respectively in wet blue hide, goatskin and pickled sheepskin was the major slaughter defect. Putrefaction was of the most common post-slaughter defect in wet blue hide (5.3\%), pickled sheepskin $(1.6 \%)$ and goatskin $(2.7 \%)$. Among the identified major defects, statistically significant reduction $(p<0.05)$ were noted in tensile strength, tear strength and percent elongation of the crust leather. Major skin and hide defects lead to considerable economical losses through reducing quality and physical performance characteristics of crust leather. Hence, innovative leather grade correction technologies are timely important.
\end{abstract}

Keywords: Defects; hide; physical characteristics; quality; skin 


\section{Introduction}

Leather industry is one of the oldest and largest industries in the global economy through its massive potential for employment, growth and exports earnings. Leather is an important input to footwear, gloves, belts, apparels and others. In the 2001, world demand for the leather and leather products was USD 24.3 billion (Adem, 2019) and it escalated to USD 347.50 billion in 2010 (TDAP, 2011). Leather upper footwear market is the biggest market amongst all the leather sub-sectors, accounting for more than $70 \%$ of the global leather consumption (TDAP, 2011) and 58.5\% of the global footwear types (IBISWorld, 2010; TDAP, 2011). Footwear consumption has been rapidly increasing worldwide from year to year; from 11 billion pairs in 1999 (Ashebre, 2014) to more than 20 billion pairs of shoes in 2005 (Shahin et al., 2007) and then estimated to be 25 billion pairs in 2018 (IBISWorld, 2010; TDAP, 2011). About $83 \%$ of the global footwear products are manufactured in Asian countries, where china shares 70\% (TDAP, 2011).

Ethiopia has the largest livestock population in Africa. The country is $10^{\text {th }}$ largest in the world with an estimated population of 60.3 million heads of cattle, 31.3 million sheep and 32.7 million goats (CSA, 2017). The animal resources gave the country a comparative advantage in raw materials needed for the leather sector. The country has a long tradition in processing and export of leather and its products. The modern leather goods industry dates back to the time when the modern tanning industry was established in mid 1920s by the Ethiopian Investment Agency (Asegedom et al., 2019). Next to coffee, leather and leather products contribute a lot for Ethiopian export earnings ( Fereja et al., 2017; Asegedom et al., 2019). However, the leather sector in Ethiopia still suffers with tremendous challenges along its value chain. Traditional husbandry management, extensive farming system, prevalence of rampant animal diseases, backyard slaughtering habit, lack of modern facilities i.e. slaughtering, preservation and transport, weak marketing system and information and lack of awareness of actors on the value chain are the major obstacles in this industry (Mesele et al., 2015; Fereja et al., 2017). Estimates of losses to the Ethiopian economy due to such problems reached US\$ 14 million per year (Solomon, 2011). Hence, this study had identified major defects of hide and skin (pre-slaughter, slaughter and post-slaughter) and determined their effect on quality and physical characteristics of crust leather. 


\section{Materials and Methods}

\section{Description of the study area}

The study conducted in Sheba Tannery and Leather Industry Private Limited Company (PLC). It is located in Wukro town in eastern zone of the Tigray Regional State, Northern Ethiopia between longitudes and latitudes of $13^{\circ} 47^{\prime}$ $59.99^{\prime \prime} \mathrm{N} 39^{\circ} 35^{\prime} 59.99^{\prime \prime} \mathrm{E}$. It is $47 \mathrm{~km}$ north from Mekelle, the capital city of the region. The tannery obtains rawhide and skin mainly from Tigray region, Addis Ababa, Gondar and Wollo areas of Amhara region. The company is one of the largest tanneries in the country that exports most of its products to Italy, China, India, Pakistan, the Netherlands, Turkey, Thailand, Malaysia and other countries. Besides, it supplies finished products like shoes and other leather articles to domestic markets (Kahsay et al., 2015; Kuria et al., 2016).

\section{Study design and sampling}

A cross-sectional study design was employed on wet blue hide, pickled sheepskin, and air-dried and salted goatskin collections of the tannery. One batch, a total of 6,530 skins and hides, of which 1,950 pickled sheep skin, 1,800 air dry goat skin, 1,780 wet salted goat skin and 1,000 wet blue hide received from the beam house operation were examined for defect type at crust leather stage. Moreover, 9,500 hides and skin (3,900 sheep skin at pickled stage, 3,600 goats at wet blue stage and 2,000 hides at wet blue) used for further analysis of defects and quality grading.

\section{Defect assessment and quality grading}

Each selected skin or hide was examined for defects (pre-slaughter, slaughter and post-slaughter) in natural light by trained skin selectors of the company and the research groups. Criteria indicated in Quality Standard Authority of Ethiopia as described in the International Organization for Standardization (Muralidharan et al., 1999) were used to identify defects and graded leather quality.

\section{Determination of effect of defects on physical characteristics of crust leather}

Crust leather is the term applied to leather, which is dried after tanning but has not yet been dyed. After descriptive analysis of data on defects observed 
(Table 1-3), top six major defects for each of hide, sheep skin and goat skin (wound, scratch, brand mark, putrefaction, knife cut and cockle) were selected for determining the effect of those defects on physical characteristics of leather (tensile strength, tear strength and percent elongation). For each defect, 5 each for wet blue goat skin, wet blue sheep skin and wet blue cattle hide were selected. Considering five skin/hide per an identified major defect, 90 samples (5 skin/hide* 6 defects $=30$ hide, 30 sheep skin and 30 goat skin) were purposively selected at crust level. All samples were collected by cutting in accordance with official sampling position as per the Society of Leather Technologist and Chemists methods IUP 2 (Kuria et al., 2016). Tensile-strength, percent elongation and tearing strength evaluation were conducted in accordance with the official method of analysis adopted by the Society of the Leather Technologists and Chemists as it has been stated by Kuria et al., (2016). Then the specimens were conditioned by keeping them in standard environment, i.e., temperature $20 \pm 2$ ${ }^{\circ} \mathrm{C}$ and relative humidity $65 \pm 2 \%$ for 48 hours before testing as it has been described in the International Organization for Standardization (Muralidharan et al., 1999).

Tensile strength test (TNS): Tensile strength indicates the overall strength of the leather. Thicknesses of the specimens were measured according to IUP/6 testing method, using a standard measuring instrument as described by Kuria et al., (2016). The cross-sectional area of each specimen calculated by multiplying its width by its thickness, and values expressed in square centimeters. The span length of the tensile test is $100 \mathrm{~mm}$ apart and the crust leather specimen clamped in the jaws so that the edges of the jaw lie along lines AB, CD (Figure. 1). The machine then run until the specimen is broken and the highest load reached taken at the breaking load. The formula is Tensile strength $\left(\mathrm{kg} / \mathrm{cm}^{2}\right)=$ Load at breaking (kg)/Cross sectional area $\left(\mathrm{cm}^{2}\right)$ (Kuria et al., 2016).

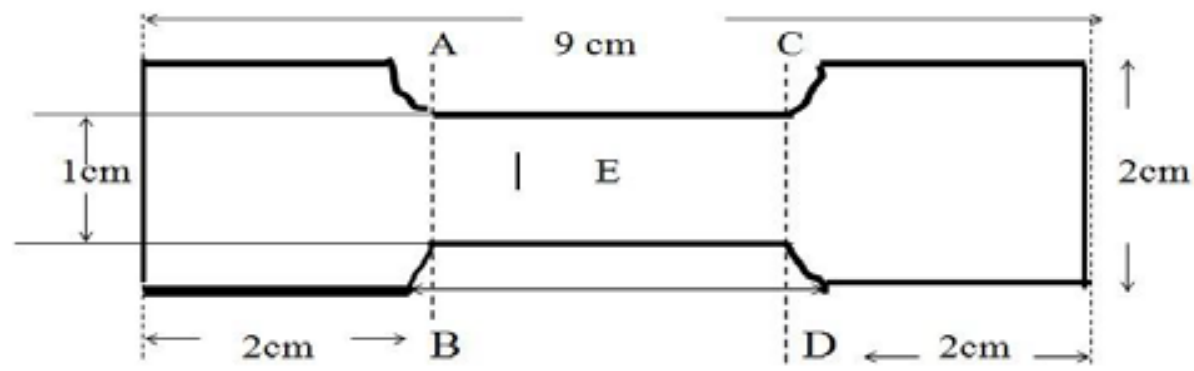

Figure 1: Schematic illustration of a standard tensile sample-Dumbbell shape (ISO 2589:2016 [IULTCS/IUP 4]). 
Tear strength (TRS): Tearing strength is the load required to continue a tear in a crust leather sample, once load is applied. There are different ways to measure tearing strength. Most common double edge tear method used in this study using the standard IUP/8 method as described by Kuria et al., (2016). The samples were punched out using a steel die of standard dimension, and taken for thickness measurement and the specimens were conditioned by keeping them in standard environment, i.e., temperature $20 \pm 2{ }^{\circ} \mathrm{C}$ and relative humidity $65 \pm 2 \%$ for 48 hours before testing (Muralidharan et al., 1999). The prepared samples were mounted in the universal tensile measuring machine (UTMM), and then the load was applied at a constant rate of $100 \mathrm{~mm} / \mathrm{min}$, till break (Kuria et al., 2016).

\section{Data analysis}

Data entry made through Excel spreadsheet version 2010 and analyzed using STATA12 statistical software. Descriptive statistics used to report percentages and counts. One sample t-test used to compare deviation of mean of physical characteristics of the selected defects against their standard. At all levels, $\mathrm{p}<0.05$ was considered statistically significant.

\section{Ethical approval and consent to participate}

A letter of request to work in the tannery was prepared and approved by the management body of the tannery. This study was conducted once a consent was obtained and necessary inputs was permitted. Examination of skins and hide for defects and physical quality performance characteristics made by willing and allowed expertise.

\section{Results}

\section{Defects of skins and hides}

In this study, wet blue hide had the highest percentage of defects. The major pre-slaughter, slaughter and post-slaughter defects were scratch (20.5\%), knife cut (21.1\%), and putrefaction (5.3\%), respectively (Table 1). On pickled sheepskin, the prevalence of pre-slaughter defect (27\%) was higher than at slaughter $(5.6 \%)$ and at post-slaughter (4.2\%). The major pre-slaughter, slaughter and post-slaughter defects on pickled sheepskin were cockle (12.7\%), knife cut $(4.5 \%)$, and putrefaction (1.6\%) respectively (Table 2). Major pre-slaughter defect of both wet blue salted and air-dried goat skin were presence of wound (14.6\%) followed by scratch marks (9.2\%) while knife cut (18\%) was the high- 
est slaughter defect (Table 3). Their effects on the quality grading and physical performance of leather were as follows.

Table 1: Pre-slaughter, slaughter and post-slaughter defects on wet blue hide

\begin{tabular}{|c|c|c|c|c|c|c|}
\hline \multirow[t]{2}{*}{ Defects } & \multicolumn{2}{|c|}{$\begin{array}{l}\text { Pre-slaughter } \\
(\mathrm{N}=1000)\end{array}$} & \multicolumn{2}{|c|}{ Slaughter $(\mathrm{N}=1000)$} & \multicolumn{2}{|c|}{ Post-slaughter $(\mathrm{N}=1000)$} \\
\hline & $\mathrm{N}$ & $\%$ & $\mathrm{n}$ & $\%$ & $\mathrm{~N}$ & $\%$ \\
\hline Brand mark & 29 & 2.9 & & & & \\
\hline Scratch & 205 & 20.5 & & & & \\
\hline LSD & 27 & 2.7 & & & & \\
\hline Wound & 17 & 1.7 & & & & \\
\hline Cockle & 61 & 6.1 & & & & \\
\hline Wart & 3 & 0.3 & & & & \\
\hline Poor pattern & & & 4 & 0.4 & & \\
\hline Hole & & & 19 & 1.9 & & \\
\hline Knife cut & & & 211 & 21.1 & & \\
\hline Machine defect & & & & & 1 & 0.1 \\
\hline Putrefaction & & & & & 53 & 5.3 \\
\hline Heat & & & & & 29 & 2.9 \\
\hline
\end{tabular}


Tsigab et al.,

Table 2: Pre-slaughter, slaughter and post-slaughter defects on pickled sheepskin

\begin{tabular}{|c|c|c|c|c|c|c|}
\hline Defects & $\begin{array}{l}\text { Pre-slaughter } \\
(\mathrm{N}=1950)\end{array}$ & & Slau & $N=1950)$ & $\begin{array}{l}\text { Post-s } \\
(\mathrm{N}=19\end{array}$ & \\
\hline & $\mathrm{N}$ & $\%$ & $\mathrm{n}$ & $\%$ & $\mathbf{n}$ & $\%$ \\
\hline Brand mark & 0 & 0 & & & & \\
\hline Scratch & 202 & 10.4 & & & & \\
\hline Pox & 19 & 0.9 & & & & \\
\hline Wound & 132 & 6.7 & & & & \\
\hline Cockle & 248 & 12.7 & & & & \\
\hline Wart & 0 & 0 & & & & \\
\hline Poor pattern & & & 9 & 0.5 & & \\
\hline Hole & & & 12 & 0.6 & & \\
\hline Knife cut & & & 87 & 4.5 & & \\
\hline Machine defect & & & & & 29 & 1.4 \\
\hline Putrefaction & & & & & 32 & 1.6 \\
\hline Heat & & & & & 24 & 1.2 \\
\hline
\end{tabular}

Table 3: Pre-slaughter, slaughter and post-slaughter defects on air dried and salted goatskin

\begin{tabular}{|c|c|c|c|c|c|c|c|c|c|c|c|c|}
\hline \multirow[t]{3}{*}{ Defects } & \multicolumn{4}{|c|}{ Pre-slaughter (3580) } & \multicolumn{4}{|c|}{ Slaughter (3580) } & \multicolumn{4}{|c|}{ Post-slaughter (3580) } \\
\hline & \multicolumn{2}{|c|}{$\begin{array}{l}\text { Dry } \\
\text { skin } \\
(\mathrm{N}=1800)\end{array}$} & \multicolumn{2}{|c|}{$\begin{array}{l}\text { Salted skin } \\
(\mathrm{N}=1780)\end{array}$} & \multicolumn{2}{|c|}{$\begin{array}{l}\text { Dry skin } \\
(\mathrm{N}=1800)\end{array}$} & \multicolumn{2}{|c|}{$\begin{array}{l}\text { Salted } \\
\text { skin } \\
(\mathrm{N}=1780)\end{array}$} & \multicolumn{2}{|c|}{$\begin{array}{l}\text { Dry skin } \\
(N=1800)\end{array}$} & \multicolumn{2}{|c|}{$\begin{array}{l}\text { Salted skin } \\
(\mathrm{N}=1780)\end{array}$} \\
\hline & $\mathbf{n}$ & $\%$ & $\mathbf{n}$ & $\%$ & $\mathbf{n}$ & $\%$ & $\mathbf{n}$ & $\%$ & $\mathbf{n}$ & $\%$ & $\mathbf{n}$ & $\%$ \\
\hline Brand mark & 3 & 0.2 & 8 & 0.4 & & & & & & & & \\
\hline Scratch & 87 & 4.8 & 82 & 4.6 & & & & & & & & \\
\hline Pox & 65 & 3.6 & 71 & 4 & & & & & & & & \\
\hline Wound & 163 & 9 & 100 & 5.6 & & & & & & & & \\
\hline Cockle & 19 & 1 & 22 & 1.2 & & & & & & & & \\
\hline Wart & 0 & 0 & 0 & 0 & & & & & & & & \\
\hline Poor pattern & & & & & 12 & 0.7 & 8 & 0.4 & & & & \\
\hline Hole & & & & & 9 & 0.5 & 7 & 0.4 & & & & \\
\hline Knife cut & & & & & 100 & 5.5 & 221 & 12.4 & & & & \\
\hline Machine defect & & & & & & & & & 13 & 0.7 & 11 & 0.6 \\
\hline Putrefaction & & & & & & & & & 15 & 0.8 & 35 & 1.9 \\
\hline Heat & & & & & & & & & 4 & 0.2 & 8 & 0.4 \\
\hline $\mathrm{N}=$ total sampled hic & e/skin; & $\mathrm{n}=\mathrm{sam}$ & les wit & defects & & & & & & & & \\
\hline
\end{tabular}




\section{Quality grading of skins and hides}

The overall rejection of skins and hides was $32.7 \%$ of which it was $23.5 \%$ for wet blue hide, $5.1 \%$ for wet blue salted and air-dried goat skin, and $4.1 \%$ for pickled sheepskins. None of the skin and hide scored grade I-III. Only $3 \%$ of wet blue salted and air-dried goatskin, $1.1 \%$ of pickled sheepskin and $0.07 \%$ of wet blue hide were of grade IV. The majority of the skin and hide were in grade VI and VII (Table 4). The distribution of defects in the quality grades of skins and hides was as shown in Tables $5-7$.

In pickled sheepskin, most defects, particularly cockle/ekek and scratch were highly distributed in grade IV-VII. The defects responsible for rejection of pickled sheepskin were cockle (18.7\%), putrefaction (15.2\%), flay cut $(10.3 \%)$, scratch $(9.5 \%)$, scar $(9.2 \%)$, poor pattern $(8.5 \%)$, pox $(7.1 \%)$, machine defect (6.4\%), poor substance (4.3\%), vein mark (4.9\%), and crack (4.6\%) (Table 5). On wet blue goatskin, most defects distributed in grade IV-VII. The defects responsible for rejection of wet blue goatskin were crack (18.9\%), cockle (18.6\%), scar (17.4\%), scratch (15.9\%), vein mark (11\%), flay cut (5.4\%), brand mark (3.4), poor pattern $(2.3 \%)$, putrefaction $(1.5 \%)$, pox $(1.5 \%)$, machine defect $(0.4 \%)$, and wound (0.4\%) (Table 6). On wet blue cattle hides; brand mark, knife cut, putrefaction and scratch marks were most important defects observed in hide quality grades of IV-VII. Defects responsible for rejection of wet blue hide were knife cut (25.6\%); putrefaction (20.2\%), scratch (15.7\%), scar (11.5\%), cockle (7.4\%), brand mark (6.4\%), wound (3.8\%), machine defect (3.5\%), poor pattern (1.6\%), tick damage $(1.6 \%)$, crack (1.3\%), lumpy skin disease $(1 \%)$, and vein mark (0.3\%) (Table 7). 
Tsigab et al.,

Table 4: Grading proportion of hide and skin in Sheba tannery and leather industry

\begin{tabular}{|c|c|c|c|c|c|c|c|c|c|c|}
\hline \multirow[t]{2}{*}{ Input type } & \multirow[t]{2}{*}{ IS } & \multirow[t]{2}{*}{ IQ } & \multicolumn{8}{|c|}{ Grades } \\
\hline & & & I & II & III & IV & V & VI & VII & Rejected \\
\hline \multirow[t]{5}{*}{ Wet blue hide } & Small & 516 & - & - & - & & 17 & 79 & 217 & 203 \\
\hline & Medium & 720 & - & - & - & 2 & 28 & 315 & 195 & 180 \\
\hline & Large & 638 & - & - & - & & 103 & 201 & 189 & 145 \\
\hline & $\begin{array}{l}\text { Extra } \\
\text { large }\end{array}$ & 978 & - & - & - & & 73 & 718 & 51 & 136 \\
\hline & Total & 2852 & - & - & - & $\begin{array}{c}2 \\
(0.07)\end{array}$ & $\begin{array}{l}221 \\
(7.4)\end{array}$ & $\begin{array}{l}1313 \\
(46)\end{array}$ & $\begin{array}{l}652 \\
(23)\end{array}$ & $664(23.5)$ \\
\hline \multirow{5}{*}{$\begin{array}{l}\text { Wet blue } \\
\text { salted and } \\
\text { dry goatskin }\end{array}$} & Small & 945 & - & - & - & 18 & 64 & 492 & 319 & 52 \\
\hline & Medium & 766 & - & - & - & 17 & 308 & 261 & 126 & 54 \\
\hline & Large & 789 & - & - & - & 39 & 323 & 271 & 119 & 37 \\
\hline & $\begin{array}{l}\text { Extra } \\
\text { large }\end{array}$ & 1003 & - & - & - & 25 & 412 & 270 & 257 & 39 \\
\hline & Total & 3503 & - & - & - & $99(3)$ & $\begin{array}{c}1107 \\
(31.6)\end{array}$ & $\begin{array}{c}1294 \\
(37)\end{array}$ & $\begin{array}{c}821 \\
(23.4)\end{array}$ & $182(5.1)$ \\
\hline \multirow{5}{*}{$\begin{array}{l}\text { pickled } \\
\text { sheepskin }\end{array}$} & Small & 945 & - & - & - & 12 & 58 & 500 & 325 & 50 \\
\hline & Medium & 766 & - & - & - & 5 & 363 & 249 & 103 & 46 \\
\hline & Large & 789 & - & - & - & & 391 & 298 & 93 & 7 \\
\hline & $\begin{array}{l}\text { Extra } \\
\text { large }\end{array}$ & 1003 & - & - & - & 23 & 412 & 267 & 260 & 41 \\
\hline & Total & 3503 & - & - & - & $\begin{array}{c}40 \\
(1.1)\end{array}$ & $\begin{array}{c}1224 \\
(35)\end{array}$ & $\begin{array}{c}1314 \\
(37.5)\end{array}$ & $\begin{array}{c}781 \\
(22.2)\end{array}$ & $144(4.1)$ \\
\hline
\end{tabular}


Table 5: Distribution of defects on sheep skin at pickled stage in different quality grades $(\mathrm{N}=3900)$

\begin{tabular}{|c|c|c|c|c|c|c|c|c|c|}
\hline \multirow[t]{3}{*}{ Type of defects } & \multicolumn{9}{|c|}{ Grade } \\
\hline & \multicolumn{2}{|l|}{ IV } & \multicolumn{2}{|l|}{ V } & \multicolumn{2}{|l|}{ VI } & \multicolumn{2}{|c|}{ VII/rejected } & \multirow[t]{2}{*}{ Total } \\
\hline & $\mathbf{n}$ & $\%$ & $\mathbf{n}$ & $\%$ & $\mathbf{n}$ & $\%$ & $\mathbf{n}$ & $\%$ & \\
\hline Cockle/ekek & 59 & 19.5 & 43 & 14.5 & 38 & 16.7 & 53 & 18.7 & 193 \\
\hline Scratch & 47 & 15.6 & 54 & 18.2 & 35 & 15.4 & 27 & 9.5 & 163 \\
\hline Flay cut & 29 & 9.6 & 38 & 12.8 & 20 & 8.8 & 30 & 10.6 & 113 \\
\hline Scar & 22 & 7.3 & 26 & 8.8 & 23 & 10.1 & 26 & 9.2 & 97 \\
\hline Crack & 24 & 7.9 & 22 & 7.4 & 18 & 7.9 & 13 & 4.6 & 77 \\
\hline Veins & 34 & 11.3 & 24 & 8.1 & 13 & 5.7 & 14 & 4.9 & 85 \\
\hline Putrefaction & 20 & 6.6 & 21 & 7.1 & 31 & 13.6 & 43 & 15.2 & 115 \\
\hline Poor pattern & 23 & 7.6 & 20 & 6.8 & 15 & 6.6 & 24 & 8.5 & 82 \\
\hline Pox & 19 & 6.3 & 15 & 5.1 & 12 & 5.3 & 20 & 7.1 & 66 \\
\hline Machine defect & 13 & 4.3 & 22 & 7.4 & 12 & 5.3 & 18 & 6.4 & 65 \\
\hline Poor substance & 12 & 4.0 & 11 & 3.7 & 11 & 4.8 & 15 & 5.3 & 49 \\
\hline Total defects & 302 & & 296 & & 228 & & 283 & & 1105 \\
\hline
\end{tabular}


Tsigab et al.,

Table 6: Distribution of defects on goat wet blue stage in different quality grades $(\mathrm{N}=3600)$

\begin{tabular}{|c|c|c|c|c|c|c|c|c|c|}
\hline \multirow[t]{3}{*}{ Defects } & \multicolumn{9}{|c|}{ Grade } \\
\hline & \multicolumn{2}{|l|}{ IV } & \multicolumn{2}{|l|}{ V } & \multicolumn{2}{|l|}{ VI } & \multicolumn{2}{|c|}{ VII/reject } & \multirow[t]{2}{*}{ Total } \\
\hline & $\mathbf{n}$ & $\%$ & $\mathbf{n}$ & $\%$ & $\mathbf{n}$ & $\%$ & $\mathbf{N}$ & $\%$ & \\
\hline Cockle/ekek & 19 & 15.4 & 66 & 21.6 & 59 & 19.8 & 49 & 18.6 & 193 \\
\hline Scratch & 11 & 8.9 & 42 & 13.8 & 35 & 11.7 & 42 & 15.9 & 130 \\
\hline Flay cut & 6 & 4.9 & 18 & 5.9 & 9 & 9.7 & 43 & 16.3 & 76 \\
\hline Scar & 12 & 9.8 & 53 & 17.4 & 55 & 18.5 & 46 & 17.4 & 166 \\
\hline Crack & 13 & 10.6 & 45 & 14.8 & 52 & 17.4 & 50 & 18.9 & 160 \\
\hline Veins & 49 & 39.8 & 56 & 18.4 & 47 & 15.8 & 29 & 11.0 & 181 \\
\hline Putrefaction & 3 & 2.4 & 5 & 1.6 & 6 & 2.0 & 4 & 1.5 & 18 \\
\hline Poor pattern & 3 & 2.4 & 7 & 2.3 & 5 & 1.7 & 6 & 2.3 & 21 \\
\hline Pox & 2 & 1.6 & 2 & 0.7 & 2 & 0.7 & 4 & 1.5 & 10 \\
\hline Brand mark & 0 & - & 3 & 1.0 & 2 & 0.7 & 9 & 3.4 & 17 \\
\hline $\begin{array}{l}\text { Machine } \\
\text { defect }\end{array}$ & 2 & 1.6 & 2 & 0.7 & 0 & - & 1 & 0.4 & 5 \\
\hline Wound & 2 & 1.6 & 2 & 0.7 & 1 & 0.3 & 1 & 0.4 & 6 \\
\hline Hole & 1 & 0.8 & 2 & 0.7 & 2 & 0.7 & 0 & - & 5 \\
\hline Total grade & 123 & & 305 & & 298 & & 264 & & 988 \\
\hline
\end{tabular}


Table 7: Distributions of defects on wet blue hide stage in different grades (N=2000)

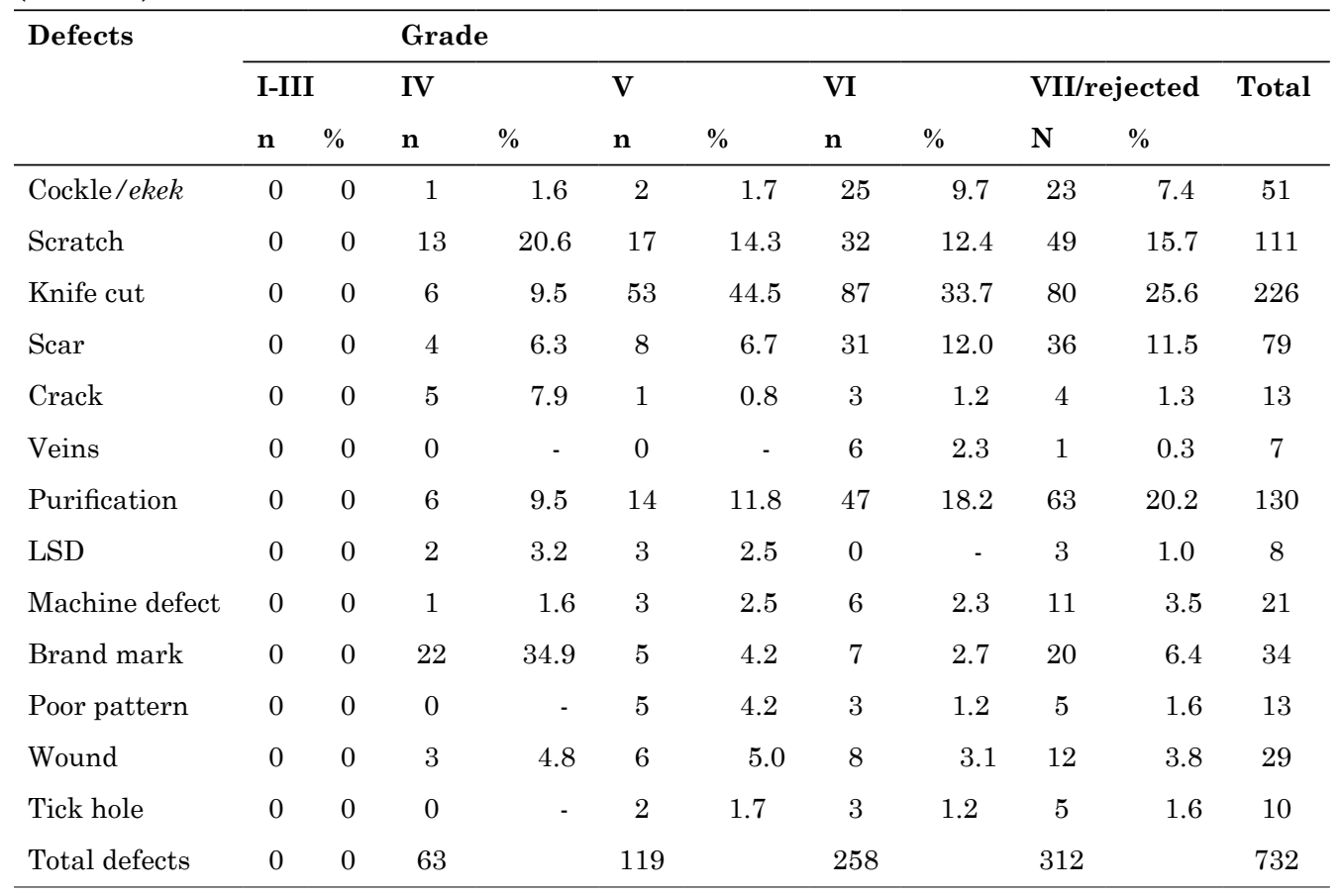




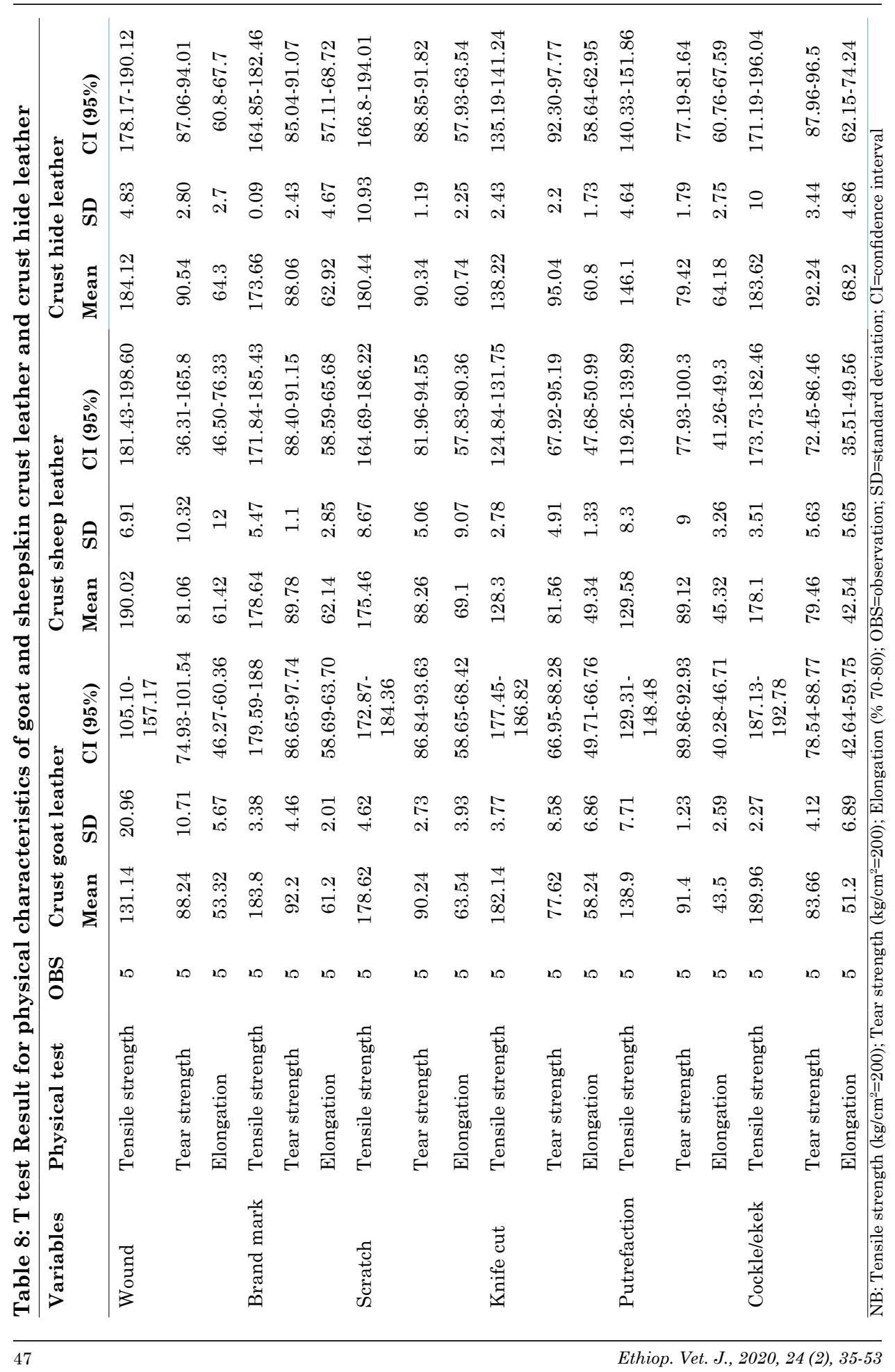




\section{Effect of skin and hide defects on physical characteristics of crust leather}

Normal standards values of TNS $\left(200 \mathrm{~kg} / \mathrm{cm}^{2}\right)$; TRS $\left(200 \mathrm{~kg} / \mathrm{cm}^{2}\right)$; PEL (70$80 \%)$ were compared with measurements of crust leather of skins and hides affected by either of wound, scratch, brand mark, putrefaction, knife cut or cockle. The difference in mean of the five measurements of each defect compared to the standard of the TNS, TRS and PEL was statistically significant $(p<0.05)($ Tables 8).

\section{Discussion}

The quality of the rawhide and skin plays a decisive role on the quality of the leather and its' constituents. Quality of rawhide and skin is largely dependent on the extent of ante-mortem and postmortem defects. Slaughter and postmortem defects are controllable to certain extent, while ante-mortem defects pose serious challenges to tanneries (Habib et al., 2015). Scratch was the most frequent pre-slaughter defect of hides. Kahsay et al., (Kahsay et al., 2015) had a similar observation in Sheba Tannery. However, Urgessa (2013) had reported cockle as most frequent pre-slaughter defect of hide from Addis Ababa and Modjo tanneries. These variations might be due to the differences in agroecology, deworming activities husbandry managements and the season that samples had collected. Agroecology that affects quality of feed and texture of the skin and hide reflects the substance or quality nature of the skin and hide whereas poor husbandry practices downgrade it. Cockle was the most frequent pre-slaughter defects on pickled sheepskin. The finding was in agreement with reports of Ashenafi et al., (2013) in Sheba Tannery and in Addis Ababa and Modjo (Urgessa, 2013). In wet blue goat skin, wound was most frequent preslaughter defect observed in the current study although cockle (Urgessa, 2013) and scratch (Sertse and Wossene, 2007) were reported from Addis Ababa and Modjo, and Sebeta, respectively.

Of the slaughter defects, knife cut was most frequently observed slaughter defect on hide and skin which was in agreement with Berhe (2009) from Sheba tannery and leather industry. However, poor pattern was reported with high- 
est frequency in Bahirdar (Zembaba et al., 2012). Likewise, Hailu, (2013) had also reported poor pattern as a slaughter defect of sheep and goats skin in many of the municipal abattoirs in the country. It might be due to skill and awareness of butchers. Commonly practiced backyard slaughtering habit of the community may also have great role for both defects.

Among the post-slaughter defects, putrefaction was in highest percentage on hide and skin. This finding was in agreement with those reported by Behailu (2015) from Colba (Ashenafi et al., 2013) and Sheba tanneries (Ahenafi et al., 2013). The prevalence of putrefaction was at higher rate on wet blue hide as compared to wet blue skin. This finding was in agreement with those reported by Kahsay et al., (2015) from Sheba tannery and Yacob et al., (2008). Most of the post-slaughter defects are due to poor management or improper preservation and storage of skin and hide.

The observed defects have reduced the quality grading and resulted in significant reduction. Larger proportion of wet blue hide rejected, followed by wet blue goatskin. (Ashenafi et al., 2013) had also reported financial loss of around USD 800, 000.00 and USD 250, 000.00 due to cockle defect-based rejection of pickled sheep and wet blue goatskin, respectively. The dominant defects were cockle, which were higher in both sheep and goatskin than hide. This was in line with the result observed by Berhanu et al., (2011) and Asefa et al., (2012) who had reported cockle as leading defects on sheep skin rejection. However, Kahsay et al., (2015) had reported scratch as the dominant defect of sheep skin, goat skin and hide.

During the current study, none of the skin and hides scored I-III quality grade which was unlike to the observations of (Behailu, 2015) who had reported only 8.8\% from Colba tannery. Most of the skins and hides of this study scored quality grades of VI-VII which was in line with reports of $69 \%$ by Behailu from Colba tannery and $69.6 \%$ by Urgessa (2013) from tanneries in Addis Ababa and Modjo. The overall hide and skin rejection in this study was 32.7\% of which $23.5 \%$ was wet blue hide, $5.1 \%$ for wet blue salted and dry goatskin and $4.1 \%$ for pickled sheepskin. Degrading and rejection of skin and hide after beam house operation incurs loss of cost of purchase and processing and subsequently incurring extra cost for correction during finishing or total rejection (Solomon, 2011 and Teklay et al., 2019).

Measurable properties of leather are physical properties such as tensile properties that determines the structural resistance of leather to tensile forces, 
hence its state and usability (Habib et al., 2015). Understanding the changes made on physical properties due to the various defects is a prerequisite for identification and development of leather defect correction technology through synthesis and application of selected tanning agent or filler material.

Percentage Elongation determines the elasticity of the material especially upper leather and footwear upper should possess high flexibility to prevent the appearance of cracks and tears in the ball area. High elasticity allows the material to withstand the elongation stresses to which it is subjected during footwear lasting, especially on the toe area (Nalyanya et al., 2013). In this study, compared to standards, there was reduction in the mean differences of Tensile strength, Tear strength and percent elongation measurements of the skins and hides with any of the major defects (wound, scratch, brand mark, putrefaction, knife cut or cockle). This signifies serious damages attributed to poor quality leather, characterized by reduced percent elongation, elasticity, and tear strength. This seriously reduces quality of the raw materials required for finished products, thereby, a drop in the national economy.

\section{Conclusion}

Various skin and hide defects were identified among which pre-slaughter defects took higher proportion followed by slaughter defects. The defects seriously affected quality grading and significantly reduced tensile strength, percent elongation and tear strength. Rejection of the defective skin and hides incurs serious financial loss across the raw skin and hides marketing value chain and beam house operations. Therefore, we recommend further research on novel grade correction technologies of leather. Moreover, policies and actions on improved animal husbandry and locally feasible animal diseases control policies should be established in the country.

\section{Competing Interests}

The authors declare that they have no competing interests.

\section{Acknowledgments}

The staffs of the Sheba Tannery and Leather Industry are acknowledged for their technical support during the study. The study received financial support from large and medium scale project schemes of Mekelle University. 


\section{References}

Adem, M., 2019. Production of hide and skin in Ethiopia; marketing opportunities and constraints: A review paper. Cogent Food \& Agri., 5, 1-9.

Asegedom, B.H., Mezgebe, T.T., Desta, A., 2019. Analyzing the causes of rejection and downgrading of semi-finished products in Ethiopian leather and leather industries: situational analysis of semi-finished products from the Sheba leather industry. Int. J. Eco. Res, 7, 92-119.

Ashebre, M., 2014. Performance of Leather Uppers of Local Footwear products and the Determinants. Int. J. Adv. Res. Tech., 3(3), 26-30.

Ashenafi, H., A., Tolossa, H.Y., Yebegaeshet, M., 2013. Impact of sheep and goats ectoparasites on the tanning industry in Tigray Region, Ethiopia. Ethiop. Vet. J., 17(2), 63-76.

Assefa, M., Tesfaye, D., Taye, M., 2012. A study on the prevalence of sheep and goat skin defects in Bahir dar tannery, Ethiopia. Online J. Anim. Feed Res., 2 (4)-384387.

Behailu, A., 2015. Assessment of pre and post-slaughter hide and skin defects and their association with carcass condemnation in two woredas of east area zone, Ethiopia. DVM thesis, College of Veterinary Medicine and Agriculture, Addis Ababa University.

Berhanu, W., Negussie, H., Alemu, S., Mazengia, H., 2011. Assessment on major factors that cause skin rejection at Modjo export tannery, Ethiopia. Trop. Anim Hlth. Prod., 43(5), 989-993.

Berhe, A.N., 2009. Assessment of hides and skins marketing in Tigrai region: the case of Atsbi wemberta wereda, Eastern Tigrai. MA thesis, College of Development Studies, Addis Ababa University, Addis Ababa, Ethiopia.

CSA, 2017. Central Statistical Authority (CSA) of Federal Democratic Republic of Ethiopia: Agricultural sample report on livestock and livestock characteristics. Addis Ababa, Ethiopia.

Fereja, G.B., Lamaro, M., Berhe, G., Berhe, A., 2017. Study on production potential and preservation methods of hide and skin in three selected districts of Gambella region, South West Ethiopia. Int. J. Res. Granthaalayah., 5(2), 142-150.

Habib, A.B., Noor, I.A., Musa, A.E., 2015. Effect of some Skin Defects on Physical Properties of the Leather. J. Appl. Sci. Eng., 3(3), 112-119.

Hailu, Y., 2013. Skin Defects in Small Ruminates and Their Nature and Economic Importance: The Case of Ethiopia. Global Vet., 11(5), 552-559.

IBISWorld, 2010. Global Footwear Manufacturing: C1321-GL. pp. 1-37. 
'ISO 2589:2016 [IULTCS/IUP 4] Leather Physical and mechanical tests - Determination of thickness. Accessed from https://www.iso.org/standard/68859.html on 21 October 2020'

Kahsay, T., Negash, G., Hagos, Y., Hadush, B., 2015. Pre-slaughter, slaughter and postslaughter defects of skins and hides at the Sheba Tannery and Leather Industry, Tigray region, northern Ethiopia. Onderstepoort J. Vet. Res., 82(1), 1-7.

Kuria, A., Ombui, J., Onyuka, A., Sasia, A., Kipyegon, C., Kaimenyi, P., Ngugi, A., 2016. Quality Evaluation of Leathers Produced By Selected Vegetable Tanning Materials from Laikipia County, Kenya. IOSR-JAVS, 9(4), 13-17.

Mesele, A., Abrha, B., Yohannes, H., Getachew, G., 2015. Livestock Market Value Chain Assessment in Selected Sites of Tigray, North Ethiopia: Challenges and Opportunities for Enhancing Animal Product Export. Global Vet. 14(1), 48-55.

Muralidharan, C., Vega, I., Reid, D., 1999. Guidelines for grading sheep and goat skins and hide on the basis of mass, size, and defects. Inter. Org. Standardization (ISO/ TC 120/SC 1). pp. 1-10.

Nalyanya, K.M., Rop, R.K., Onyuka, A., Kamau, J., 2013. Tensile Properties of Indigenous Kenyan Boran Pickled and Tanned Bovine Hide. IJSR 4(3), 2149-2154.

Sertse, T., Wossene, A., 2007. Effect of ectoparasites on quality of pickled skins and their impact on the tanning industries in Amhara regional state, Ethiopia. Small Ruminant Res., 69(1-3), 55-61.

Shahin, R., T Theodros, Gareth, C., 2007. Recycling of Footwear Products. A position paper by Centre for Sustainable Manufacturing and Reuse/recycling Technologies (SMART) Loughborough University. pp. 1-17.

Solomon, WH., 2011. Impact of ectoparasite control campaign on quality of processed skins in tanneries of the Amhara Regional Government: a rapid assessment. Ethiop. Vet. J. 15(1), 103-115.

TDAP, 2011. Leather Market in China. Trade Development Authority of Pakistan (TDAP): Commercial Section, Consulate General of Pakistan Chengdu, China. pp. $1-33$.

Teklay, A., Gebeyehu, G., Getachew, T., Yaynshet, T., and Sastry, T. P., 2019. Ethiopian Hides and Skin Defects and Quality Status: An Assessment at Wet Blue Stage. J. Waste Manage Xenobio., 2(3): 000130.

Urgessa, B.G., 2013. Defect Assessment of Ethiopian Hide and Skin: The Case of Tanneries in Addis Ababa and Modjo, Ethiopia. Global Vet., 11, 395-398.

Ethiop. Vet. J., 2020, 24 (2), 35-53 
Tsigab et al.,

Yacob. H.T., Netsanet, B., Dinka, A., 2008. Prevalence of major skin diseases in cattle, sheep and goats at Adama Veterinary Clinic, Oromia regional state, Ethiopia. Revue Méd. Vét., 159 (8-9), 455-461.

Zembaba, T., Mengesha, D., Negash, T., Melaku, S., Garedew, L., 2012. Stereotyping of Defects and Grading of Raw Sheep and Goat Skins Collected and Stored by Skin Traders in Bahir-Dar Town, Ethiopia. Int. J. Anim. Vet. Adv., 5(1), 15-20. 